Research Article

\title{
Incidence, Risk Factors, and Outcomes of Perioperative Atrial Fibrillation following Noncardiothoracic Surgery: A Systematic Review and Meta-Regression Analysis of Observational Studies
}

\author{
Yamini Subramani $\mathbb{D D}^{1}{ }^{1}$ Omar El Tohamy, ${ }^{2}$ Daniil Jalali, ${ }^{2}$ Mahesh Nagappa, ${ }^{1}$ Homer Yang, \\ and Ashraf Fayad \\ ${ }^{1}$ Department of Anesthesia and Perioperative Medicine, London Health Sciences Centre and St. Joseph Health Care, \\ Western University, Schulich School of Medicine and Dentistry, London, Ontario, Canada \\ ${ }^{2}$ Department of Medical Sciences, Western University, London, Ontario, Canada
}

Correspondence should be addressed to Yamini Subramani; yaminisrs@rediffmail.com

Received 18 January 2021; Revised 8 April 2021; Accepted 19 April 2021; Published 28 April 2021

Academic Editor: Yukio Hayashi

Copyright (c) 2021 Yamini Subramani et al. This is an open access article distributed under the Creative Commons Attribution License, which permits unrestricted use, distribution, and reproduction in any medium, provided the original work is properly cited.

\begin{abstract}
Background. Atrial fibrillation (AF) occurs in $16-30 \%$ of patients after cardiac and thoracic surgery and can lead to serious complications like hypoperfusion of vital organs, pulmonary edema, and myocardial infarction. The evidence on risk factors and complications associated with perioperative AF after noncardiothoracic surgery is limited. Methods. The primary objective was to determine demographic and clinical risk factors for new-onset atrial fibrillation associated with noncardiothoracic surgery. A secondary aim was to identify the incidence and odds of perioperative complications associated with the new-onset atrial fibrillation. A systematic search within multiple databases was conducted for studies that explicitly reported on new-onset atrial fibrillation after noncardiothoracic surgery. We reported data on demographics, comorbidities, and perioperative complications as mean difference (MD) or odds ratios (OR) and corresponding 95\% confidence interval (CI) using random effects models. A two-sided $P$ value of less than 0.05 was considered significant. We performed meta-regression and sensitivity analysis of various subgroups to confirm the inference of our findings. Results. Eleven studies reporting on 121,517 patients were included, of whom 2,944 developed perioperative AF (incidence rate: 3.7\%; 95\% CI: $2.3 \%--6.2 \%$ ). Advanced age (AF group versus control group: $69.36 \pm 10.5$ versus $64.37 \pm 9.53$ years; MD: 4.06 ; $95 \%$ CI: $1.67--6.44 ; P=0.0009)$, male gender (52.85\% versus $43.59 \%$; OR: 1.08 ; $95 \%$ CI: 0.54 to $\left.1.62 ; I^{2}: 84 \% ; P<0.0001\right)$, preoperative hypertension $\left(60.42 \%\right.$ versus $56.51 \%$; OR: $1.15 ; 95 \%$ CI: 1.08 to $1.23 ; I^{2}: 0 \%$; $P<0.00001)$, diabetes mellitus $\left(22.6 \%\right.$ versus $23.04 \%$; OR: $0.97 ; 95 \%$ CI: 0.89 to $\left.1.05 ; I^{2}: 0 ; P<0.00001\right)$, and cardiac disease (30.64\% versus $8.49 \%$; OR: 2.3 ; $95 \%$ CI: 0.28 to $4.31 ; I^{2}: 93 \% ; P=0.03$ ) were found to be significant predictors for perioperative AF. The AF group was at increased odds of developing postoperative cardiac complications (34.1\% versus 5\%; OR: 5.44 ; $95 \%$ CI: 0.49 to $\left.10.39 ; I^{2}: 82 \% ; P=0.03\right)$, postoperative stroke ( $0.5 \%$ versus $0.1 \%$; OR: $3 ; 95 \%$ CI: 0.65 to $\left.5.35 ; I^{2}: 0 \% ; P=0.01\right)$, and mortality (7.40\% versus $1.92 \%$; OR: 3.58 ; $95 \%$ CI: 0.14 to $7.02 ; I^{2}: 0 \% ; P=0.04$ ). Study quality assessment by meta-regression and sensitivity analysis of the various subgroups did not affect the final inference of the results. Conclusion. We identified advanced age, male gender, preoperative hypertension, diabetes mellitus, and cardiac disease as important risk factors for perioperative atrial fibrillation. The atrial fibrillation group was at increased odds for postoperative cardiac complications, stroke, and higher mortality, emphasizing the need for risk stratification and close monitoring.
\end{abstract}

\section{Introduction}

Atrial fibrillation (AF) occurs in $16-30 \%$ of patients after cardiac and thoracic surgery [1-4], secondary to direct mechanical irritation of the myocardium or pericardium. Perioperative AF is associated with an increased risk of inhospital morbidity and mortality [5]. Atrial arrhythmias are the most frequent rhythm disturbances in the postoperative 
period [6], and ventricular arrhythmias and brady arrhythmias are less frequent. The pathophysiology of AF associated with noncardiothoracic surgery is poorly understood but is thought to be due to inflammatory postoperative response triggering a disorganized electrical activity within atrial myocytes [7]. In addition, surgery and anesthesia are associated with a stress-induced increased sympathetic activity, thereby predisposing the patient to arrhythmias $[8,9]$. There are several studies in the literature which largely focus on perioperative AF following cardiothoracic surgery $[3,4,10,11]$. But the evidence concerning perioperative AF following noncardiothoracic surgery is limited. An increase in the number of ageing surgical populations over the last decade has increased the overall prevalence of postoperative AF [12-14]. Hence, it is important to identify the risk factors and outcomes associated with perioperative AF to characterize those patients at risk of postoperative complications. The primary objective of this systematic review and meta-analysis (SRMA) is to identify the risk factors associated with perioperative AF during noncardiothoracic surgery. The secondary objective is to identify any perioperative complications associated with perioperative AF.

\section{Methods}

This SRMA was conducted with a predesigned protocol (Supplementary File S1), which is registered at PROSPERO (CRD42019131060). This meta-analysis is reported as per the Preferred Items for Systematic Reviews and Meta-Analyses (PRISMA) guidelines [15].

2.1. Study Selection. We included studies which reported on perioperative $\mathrm{AF}$ in adult patients ( $>18$ years), along with a control group, after noncardiothoracic surgery. Perioperative $\mathrm{AF}$ is defined as that identified in the intraoperative/postoperative period, as a single occurrence on electrocardiogram (ECG) or a series of recordings on a 24-h ECG, with an onset within 30 days of the surgery. We did not have a fixed ECG definition for the AF, which could be symptomatic or asymptomatic and paroxysmal or persistent. We excluded case series, case reports, and any study without explicit and exclusive reporting of perioperative AF. We also excluded studies that were conducted in the cardiac and thoracic surgery setting and those studies reporting on patients with documented AF that occurred before the surgical procedures as our aim was to identify new-onset perioperative AF associated with noncardiothoracic surgeries. Abstracts and conference publications were excluded as they were not deemed to have undergone an adequate peer review process, and studies that were not published in English language were also excluded due to resource limitations.

2.2. Search Strategy. Based on predefined search criteria, an expert librarian systematically searched the following electronic databases: PubMed, Medline, Embase, Web of Science, and Cochrane databases, using the following terms and combinations of keywords, per the National Center for Biotechnology Information Medical Subject Headings (NCBI MeSH): "after surgery" or "following surgery" or "post-surgery" or "post-transplant" or "perioperative" or "periprocedural" or "intraoperative" or "intraprocedural" or "postoperative" or "postprocedural" or "perioperative period" or "arrhythmia" or "bradycardia" or "tachycardia" or "atrial flutter" or "atrial fibrillation" or "afib" or "dysrhythmia" or "tachyarrhythmia" or "bradyarrhythmia." The search was run on February 2019 and updated February 2020. The search strategy is attached as a supplementary file (S2). Three authors (OE, DJ, and YS) independently scrutinized the list of titles and abstracts, to sort out the articles to be included in the SRMA. After this, full texts of the positively screened articles were retrieved and independently assessed by two reviewers (DJ and OE) for the inclusion criteria. In case of any conflict, the senior author (AF) was consulted. Additionally, the reference lists of the included studies were hand searched for any relevant articles to be included. A modified Newcastle-Ottawa scale [16] and Quality in Prognostic Studies (QUIPS) tool [17] were used to assess the quality of the included studies.

2.3. Data Extraction. A data collection form was designed and the following data were extracted: study characteristics, including name of the author, publication year, study type, and participant number; preoperative data including age, sex, preoperative medications, cardiovascular, respiratory and general medical comorbidities, like diabetes mellitus, and hypertension; intraoperative data including type of surgery, duration, blood loss, and intraoperative cardiopulmonary complications; and postoperative data including postoperative complications like cardiopulmonary events, postoperative sepsis, stroke, and mortality. The definition and timing of the perioperative AF were recorded. The abovementioned were collected using a standardized data collection proforma. The authors YS and AF confirmed the accuracy and completeness of all the data.

2.4. Outcome Definition. The primary outcome was the demographic and clinical risk factors for new-onset perioperative AF with noncardiothoracic surgery. Secondary outcomes were the incidence and perioperative complications associated with the perioperative AF.

2.5. Quantitative Data Synthesis. Data on demographics, comorbidities, and perioperative complications were analysed by extracting and pooling odds ratios and mean differences using an inverse variance statistical method that incorporates a measure of the extent of heterogeneity into study weights, following DerSimonian and Laird's method. Continuous data were reported as mean difference (MD). Dichotomous data were reported as odds ratio (OR) and 95\% confidence interval (CI). A two-sided $P$ value of less than 0.05 was considered significant. Unless otherwise stated, we pooled unadjusted odds ratios. A pooled incidence of AF was estimated employing an epidemiological random 
effects model, using an inverse variance statistic that incorporates a measure of the extent of heterogeneity into study weights, following DerSimonian and Laird's method. Egger's test, Begg's test, fail-safe $N$-test, and inspection of the funnel plot were done to assess publication bias.

Each analysis was assessed for statistical heterogeneity using the $I$ [2] statistic [18] and chi-square test. $I$ [2] values $>50 \%$ and $P<0.05$ for the chi-square test indicate significant heterogeneity. A random effects model was used for all analyses to account for the between-study heterogeneity. Heterogeneity was further explored with an influence analysis for significant risk factors and outcomes.

An influence analysis was performed by excluding each study in the analysis for the significant risk factors and outcomes, and the pooled estimates were recalculated. If the quality or eligibility of any of the studies was in doubt, the analysis was performed by both including and excluding these studies to check the sensitivity of the pooled estimates. Study quality assessment was conducted (as categorical variable) by meta-regression and sensitivity analysis of various subgroups based on the study type (retrospective versus prospective), quality of study (good versus poormoderate), clearly defined outcomes (yes versus no), and sample size $>1000$ (yes versus no), and type of surgery (Transplant versus nontransplant procedure). The analysis was conducted using the Review Manager software (RevMan, V.5.3) and Comprehensive Meta-Analysis (CMA) software.

\section{Results}

Our initial search identified 2,973 studies, and after removing duplicates, 2,603 were screened, by titles and abstracts, to yield 51 studies for full-text eligibility review. Forty studies were excluded as they did not meet the eligibility criteria. Finally, 11 studies met the inclusion criteria and were included in this SRMA (Figure 1) [19-29]. These studies were analysed with respect to risk factors and outcomes associated with the perioperative AF. The definition of perioperative AF varied across the studies (Supplementary File S3). The 11 included studies reported on 121,517 patients undergoing noncardiothoracic surgery, of whom 2,944 developed perioperative AF. The pooled incidence of perioperative AF was $3.7 \%$ (95\% CI: $2.3 \%--6.2 \%$ ). Supplementary File S4 summarizes the systematic review of potential risk factors categorized as demographics, medical comorbidities, and postoperative complications. The quality of the included studies assessed using the modified Newcastle-Ottawa scale [16] yielded scores between 7 and 9, indicating a low risk of bias (Supplementary File S5). Supplementary File S6 shows a quality analysis using the QUIPS tool. There was a moderate to high risk of bias in confounding factor measurement as these factors were often poorly defined and measured. There was a low to moderate risk of bias in outcome measurement, as the methods to identify perioperative AF were well described in the studies. There was a low to moderate risk of bias in statistical analysis where multivariate analyses were conducted.

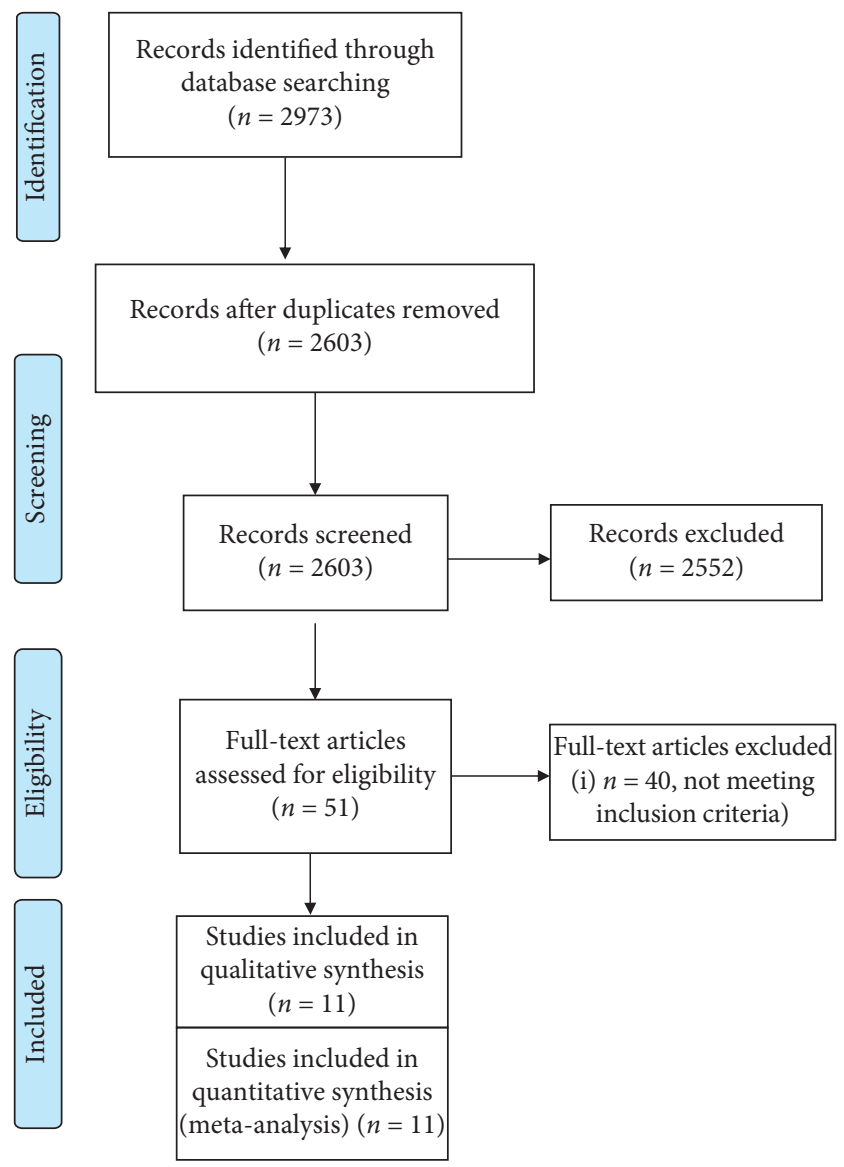

FIgURE 1: PRISMA flow diagram showing the articles screened for eligibility as per the inclusion criteria to be included in the systematic review and meta-analyses.

3.1. Demographics. Regarding age, eleven studies involving 121,517 patients reported on age: 2,944 patients in the AF group and 118,573 patients in the control group [19-29]. The average mean age in the AF group was $69.36 \pm 10.5$ years compared to $64.37 \pm 9.53$ years in the control group. Age is a significant predictor of perioperative AF (MD: 4.06; 95\% CI: 1.67 to $6.44 ; I^{2}: 88 \% ; P=0.0009$ ) (Figure 2). The impact of the Kazaure et al. study [21], explored with influence analysis, showed that MD slightly decreased and heterogeneity decreased, without changing the final inference of the study (MD: $3.54 ; 95 \%$ CI: 1.16 to $5.92 ; I^{2}$ : $72 \%$; $P=0.004)$. Egger's regression test $(P=0.0001)$ and Begg's rank test $(P=0.029)$ suggested the possibility of a publication bias; however, inspection of the funnel plot and failsafe $N$ test $(n=4433)$ did not indicate any publication bias.

Regarding gender, eleven of the included studies consisting of 121,517 patients reported on gender (perioperative AF versus control: 2944 versus 118,573) [19-29]. There was a higher incidence of perioperative AF in males versus females (perioperative AF versus control: 1556 versus 51692: 52.85\% versus $43.59 \%$; OR: 1.08 ; $95 \%$ CI: 0.54 to 1.62 ; $I^{2}$ : $84 \%$; $P<0.0001$ ) (Figure 3). When influence analysis was performed to investigate the impact of the study by Kazaure et al. [21], the OR slightly decreased and heterogeneity decreased without impacting the final inference of the results 


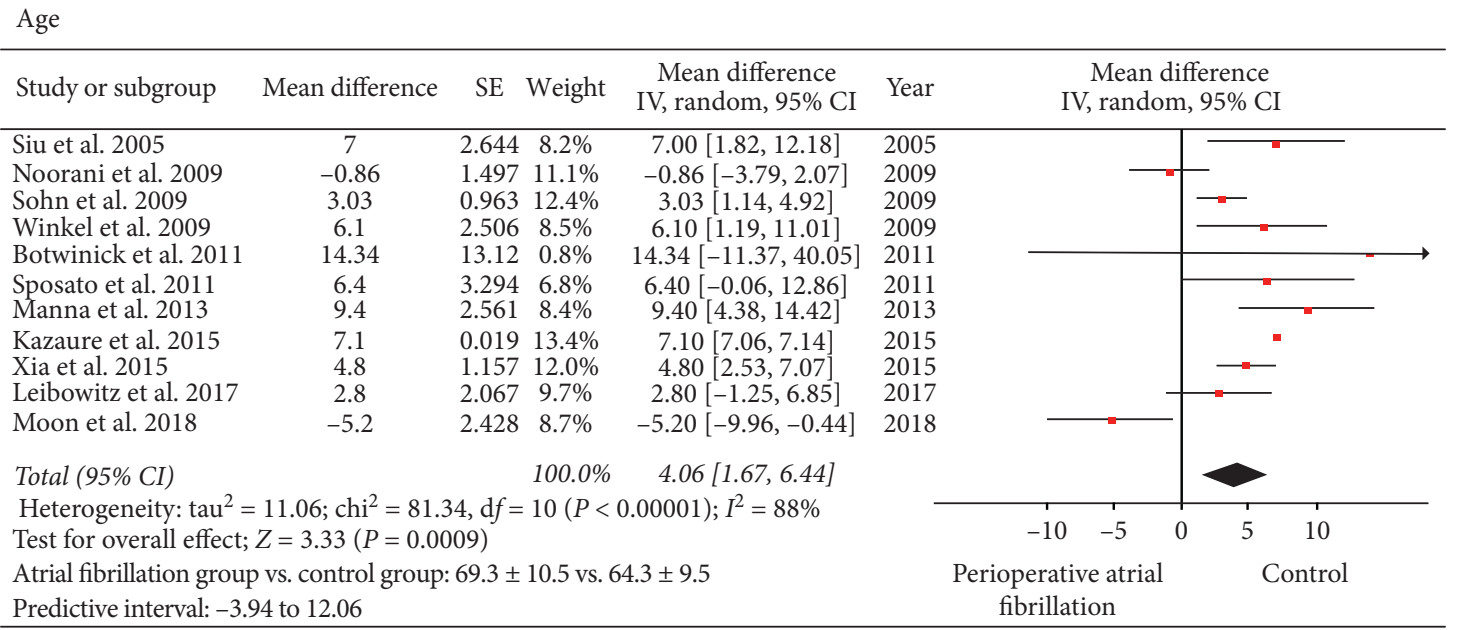

FIGURE 2: Forest plot evaluating age as a risk factor for perioperative atrial fibrillation in patients undergoing noncardiothoracic surgery. The mean difference of each included study is plotted. A pooled estimate of overall mean difference (diamonds) and $95 \%$ confidence intervals (width of diamonds) summarizes the effect size using the random effects model. $\mathrm{CI}=$ confidence interval; $\mathrm{IV}=$ inverse variance; $\mathrm{MD}=\mathrm{mean}$ difference; $I^{2}$ : heterogeneity; $P<0.05$ is significant.

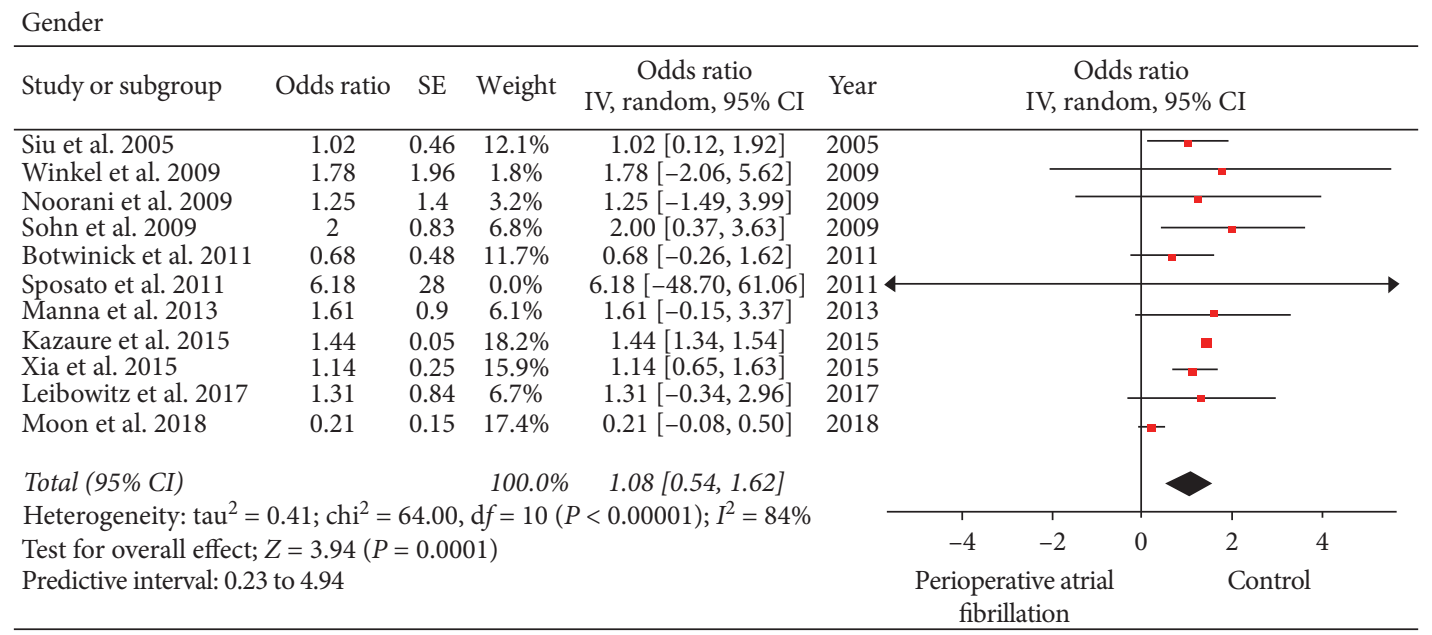

FIGURE 3: Forest plot evaluating male gender as a risk factor for perioperative atrial fibrillation in patients undergoing noncardiothoracic surgery. The odds ratio of each included study is plotted. A pooled estimate of overall odds ratio (diamonds) and $95 \%$ confidence intervals (width of diamonds) summarizes the effect size using the random effects model. $\mathrm{CI}=$ confidence interval; $\mathrm{M}-\mathrm{H}=\mathrm{Mantel}-\mathrm{Haenszel}$; $\mathrm{OR}=$ odds ratio; $I^{2}$ : heterogeneity; $P<0.05$ is significant.

(OR: $0.92 ; 95 \%$ CI: 0.45 to $1.40 ; I^{2}: 49 \% ; P=0.0001$ ). Egger's test $(P=0.322)$ and Begg's test $(P=0.876)$ did not show any publication bias.

Regarding body mass index (BMI), there was no significant difference in BMI between the perioperative AF and control group. The mean BMI was $26.67 \pm 5.52$ for the perioperative AF group compared to $24.97 \pm 3.98$ among the control group (MD: 0.18; 95\% CI: -1.14 to $1.50 ; I^{2}: 84$; $P=0.79)[19,25,27,29]$.

\subsection{Medical Comorbidities}

3.2.1. Hypertension. Ten studies consisting of 121,268 patients reported on hypertension [19, 21-29]. In AF group, out of 2931 patients, 1771 patients had hypertension, while in the control group, out of 118,337 patients, 66,876 patients had hypertension. We found that hypertension (perioperative AF versus control: $60.42 \%$ versus $56.51 \%$; OR: 1.15 ; 95\% CI: 1.08 to $\left.1.23 ; I^{2}: 0 \% ; P<0.00001\right)$ was significantly associated with perioperative AF (Figure 4). When influence analysis was performed to investigate the impact of the study by Kazaure et al. [21], the OR slightly increased and heterogeneity decreased without impacting the final inference of the results (OR: $1.26 ; 95 \%$ CI: 0.87 to $1.65 ; I^{2}: 0 \%$; $P<0.00001)$. Egger's regression test $(P=0.02684)$ suggested the possibility of a publication bias; however, Begg's rank test $(P=0.37109)$, inspection of the funnel plot, and fail-safe $N$ test $(n=27)$ did not indicate any publication bias.

3.2.2. Diabetes Mellitus. Nine of the included studies reported on diabetes [19, 21-24, 26-29]. In AF group, out of 2847 patients, 643 patients had diabetes mellitus, while in the 


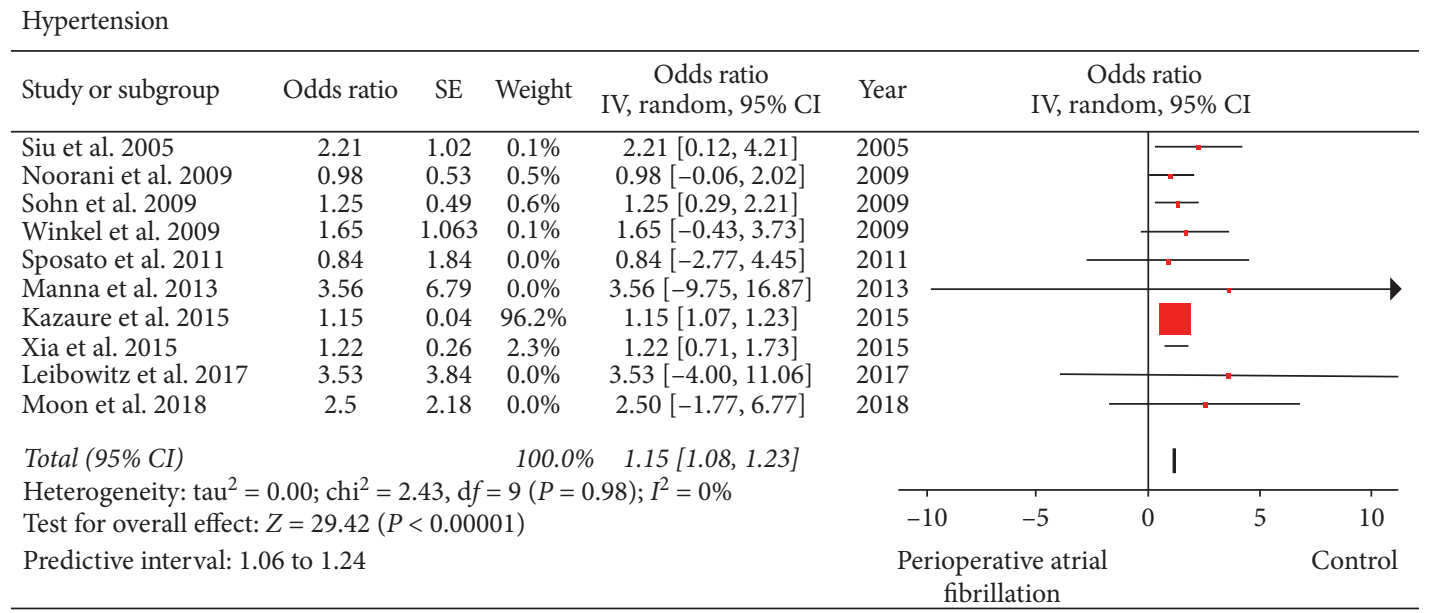

Figure 4: Forest plot evaluating hypertension as a risk factor for perioperative atrial fibrillation in patients undergoing noncardiothoracic surgery. The odds ratio of each included study is plotted. A pooled estimate of overall odds ratio (diamonds) and $95 \%$ confidence intervals (width of diamonds) summarizes the effect size using the random effects model. $\mathrm{CI}=$ confidence interval; $\mathrm{M}-\mathrm{H}=\mathrm{Mantel}-\mathrm{Haenszel}$; OR = odds ratio; $I^{2}$ : heterogeneity; $P<0.05$ is significant.

control group, out of 117,052 patients, 26,974 patients had diabetes mellitus. Diabetes mellitus was a significant predictor of perioperative $\mathrm{AF}$ (perioperative $\mathrm{AF}$ versus control: $22.6 \%$ versus $23.04 \%$; OR: 0.97 ; $95 \%$ CI: 0.89 to $1.05 ; I^{2}$ : 0 ; $P<0.00001$ ) (Figure 5). When influence analysis was performed to investigate the impact of the study by Kazaure et al. [21], the OR slightly increased without impacting the final inference of the results (OR: $0.92 ; 95 \%$ CI: 0.35 to 1.48 ; $\left.I^{2}: 0 \% ; P=0.001\right)$. Begg's test $(P=0.91697)$ and Egger's regression test $(P=0.46851)$ did not indicate presence of publication bias.

3.2.3. Cardiac Disease. Nine of the included studies with 113,512 reported on the incidence of preoperative cardiac disease (perioperative AF versus control: 2901 versus $110,611)[19,21-26,28,30]$. The presence of a cardiac disease was higher in the perioperative AF group versus control group (perioperative AF versus control: 889 versus 9399; $30.64 \%$ versus $8.49 \%$; OR: 2.3 ; $95 \%$ CI: 0.28 to 4.31 ; $I^{2}$ : $93 \%$; $P=0.03$ ) (Figure 6). Preoperative cardiac disease included ischemic heart disease, valvular heart disease, and congestive heart failure. Supplementary File S4 provides individual study data on the preoperative cardiac comorbidities in both the AF and control groups. When the impact of the study by Kazaure et al. [21] on the final inference was explored with influence analysis, the summary estimate and heterogeneity decreased without affecting the final inference of the result (OR: $1.18 ; 95 \%$ CI: 0.62 to $\left.1.75 ; I^{2}: 0 \% ; P<0.0001\right)$. Egger's regression test $(P=0.06127)$, Begg's rank test $(P=1.000)$, inspection of the funnel plot, and fail-safe $N$ test $(n=680)$ did not indicate any publication bias.

3.2.4. Respiratory Disease. Six of the included studies reported on the incidence of preoperative respiratory disease (perioperative AF versus control: 2741 versus 107,821) $[19,21-24,28]$. The presence of respiratory disease was not a significant predictor of perioperative AF (perioperative AF versus control: 478 versus 9883; 17.4\% versus 9.16\%; OR: 1.20 ; $95 \% \mathrm{CI}:-0.01$ to $\left.2.42 ; I^{2}: 77 \% ; P=0.05\right)$. The preoperative respiratory disease included chronic obstructive pulmonary disease and chronic lung disease. Supplementary File S4 provides individual study data on the preoperative respiratory comorbidities in both the arrhythmia and control groups.

3.2.5. Model for End-Stage Liver Disease (MELD) Score. Two studies involving 2446 patients reported the data on the MELD score $[25,26]$. MELD score was not a significant predictor of perioperative AF in liver transplant patients. The average MELD score was $33.5 \pm 2.8$ ( $n=115$ patients) for the AF group versus $25.2 \pm 9.1$ ( $n=2331$ patients $)$ for the control group (MD: 7.73 ; $95 \%$ CI: -0.93 to $16.4 ; I^{2}: 87 \%$; $P=0.08)$. Influence analysis by excluding and including each study did not yield any significant difference in the pooled estimate.

3.2.6. Type of Surgery. Supplementary Table S7 shows the surgery distribution for the perioperative AF and control groups. $93.20 \%$ of the patients with perioperative AF had abdominal/general surgery, followed by transplant $(4.80 \%)$, vascular (1.2\%), orthopaedic (0.51\%), and head and neck surgery (0.24\%). Similarly, in the control group, $96.69 \%$ of the patients had abdominal/general surgery, followed by transplant $(2.35 \%)$, vascular $(0.43 \%)$, orthopaedic $(0.35 \%)$, and head \& neck surgery $(0.16 \%)$.

3.3. Postoperative Complications. Cardiac complications: six of the included studies reported on the incidence of postoperative cardiac complications (perioperative AF versus control: 2771 versus 107,885) [19, 21, 22, 24, 28, 29]. The occurrence of perioperative $\mathrm{AF}$ in patients undergoing noncardiothoracic surgery was significantly associated with 


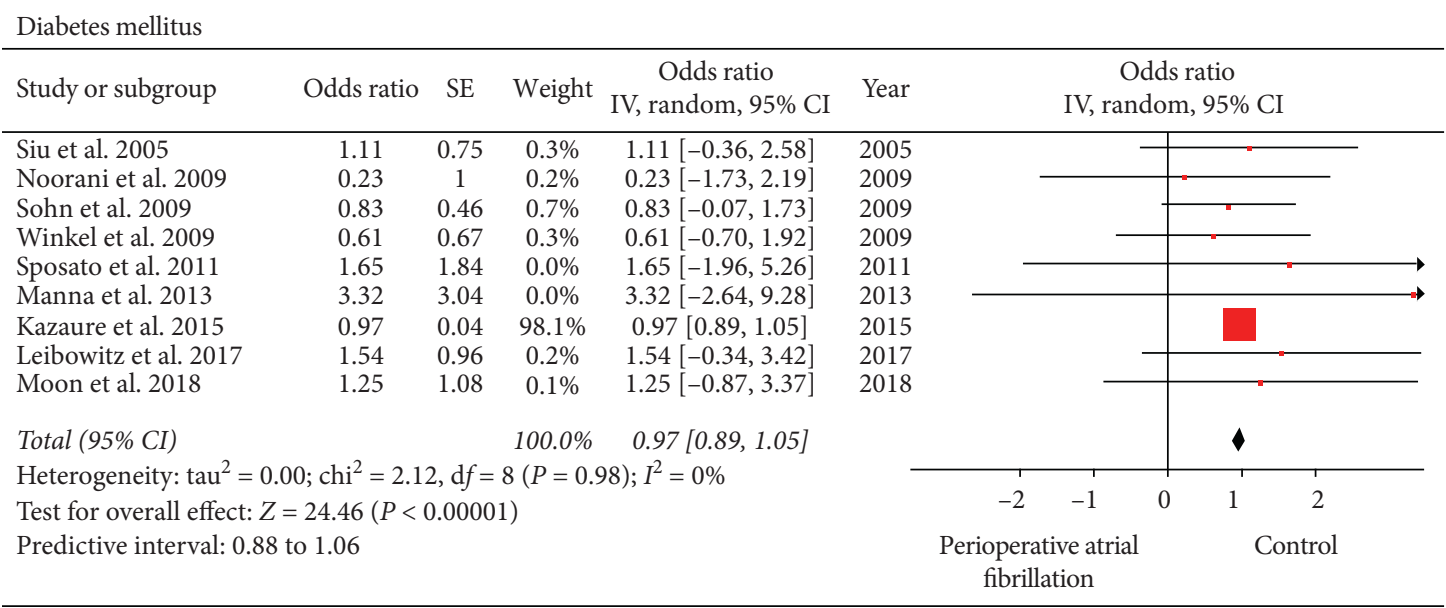

FIGURE 5: Forest plot evaluating diabetes mellitus as a risk factor for perioperative atrial fibrillation in patients undergoing noncardiothoracic surgery. The odds ratio of each included study is plotted. A pooled estimate of overall odds ratio (diamonds) and 95\% confidence intervals (width of diamonds) summarizes the effect size using the random effects model. CI=confidence interval; $\mathrm{M}-\mathrm{H}=$ Mantel-Haenszel; OR $=$ odds ratio; $I^{2}$ : heterogeneity; $P<0.05$ is significant.

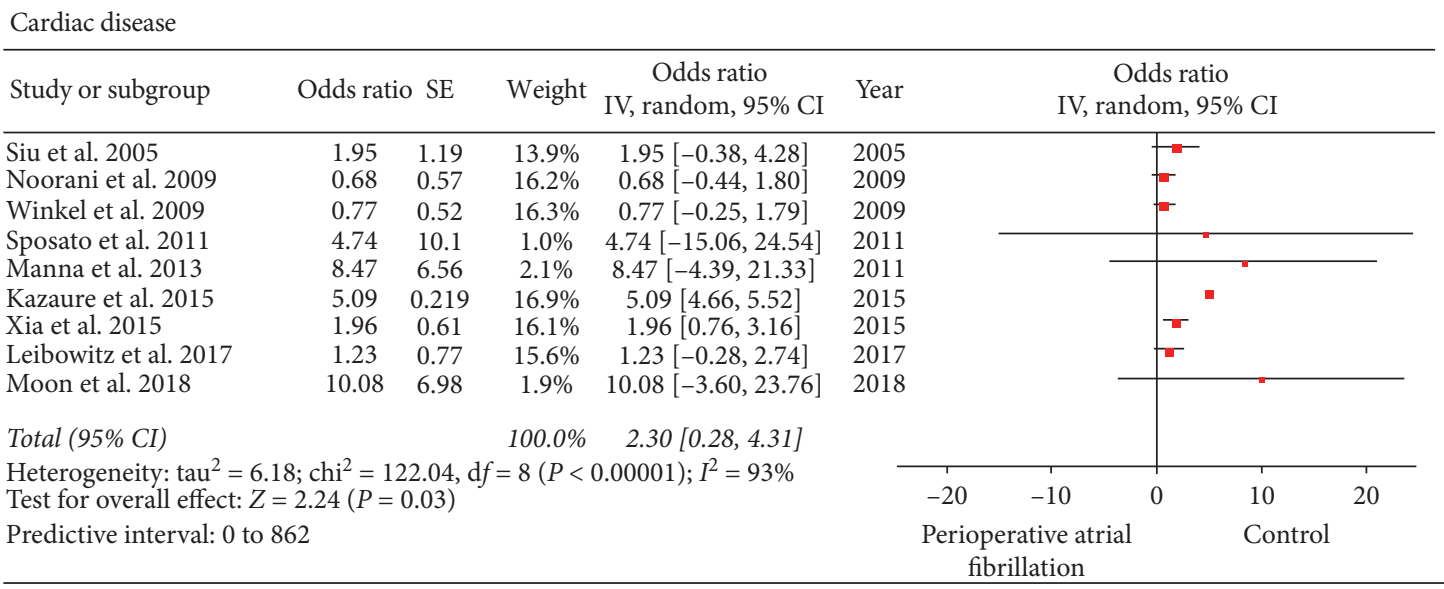

Figure 6: Forest plot evaluating cardiac disease as a risk factor for perioperative atrial fibrillation in patients undergoing noncardiothoracic surgery. The odds ratio of each included study is plotted. A pooled estimate of overall odds ratio (diamonds) and $95 \%$ confidence intervals (width of diamonds) summarizes the effect size using the random effects model. $\mathrm{CI}=$ confidence interval; $\mathrm{M}-\mathrm{H}=\mathrm{Mantel}-\mathrm{Haenszel}$; OR = odds ratio; $I^{2}$ : heterogeneity; $P<0.05$ is significant.

postoperative cardiac complications (perioperative $\mathrm{AF}$ versus control: 973 versus 5432; 34.1\% versus 5\%; OR: 5.44 ; 95\% CI: 0.49 to $10.39 ; I^{2}: 82 \% ; P=0.03$ ) (Figure 7). Postoperative cardiac complications included myocardial infarction and congestive heart failure. Supplementary File S4 provides individual study data on the postoperative cardiac complications in both the AF and control groups. The study by Kazaure et al. [21] contributed maximum heterogeneity. When this study was excluded, the heterogeneity became $0 \%$, and the final inference of the result did not change although the summary estimate decreased (OR: 3.18; 95\% CI: 0.54 to $\left.5.82 ; I^{2}: 0 \% ; P=0.02\right)$. Inspection of the funnel plot, Egger's test $(P=0.11711)$, and Begg's test $(P=1.0)$ did not indicate any publication bias.

Stroke: two studies involving 2686 patients in the AF group and 106586 patients in the control group reported the data on the stroke $[21,22]$. Perioperative arrhythmia was significantly associated with postoperative stroke (perioperative arrhythmia vs Control: 15 versus 108; $0.5 \%$ versus $0.1 \%$; OR: 3 ; $95 \% \mathrm{CI}: 0.65$ to $5.35 ; I^{2}: 0 \% ; P=0.01$; not shown in the figure).

Mortality: six studies involving 108 patients in the AF group and 9905 patients in the control group reported the data on the mortality $[19,20,22,26-28]$. Perioperative AF was a significant predictor of postoperative mortality. From the 6 studies reporting on mortality outcomes, $7.40 \%$ had perioperative mortality in arrhythmia group versus $1.92 \%$ in control group (perioperative AF versus control: 8 versus 191; OR: 3.58 ; 95\% CI: 0.14 to $7.02 ; I^{2}: 0 \% ; P=0.04$ ) (Figure 8 ). Inspection of the funnel plot, Egger's test $(P=0.33536)$, Begg's test $(P=0.80650)$, and fail-safe $N$ test $(n=27)$ did not indicate any publication bias.

Study quality assessment: study quality assessment was conducted (as categorical variable) by meta-regression and sensitivity analysis of various subgroups based on the study type (retrospective versus prospective), quality of study 
Cardiac complications

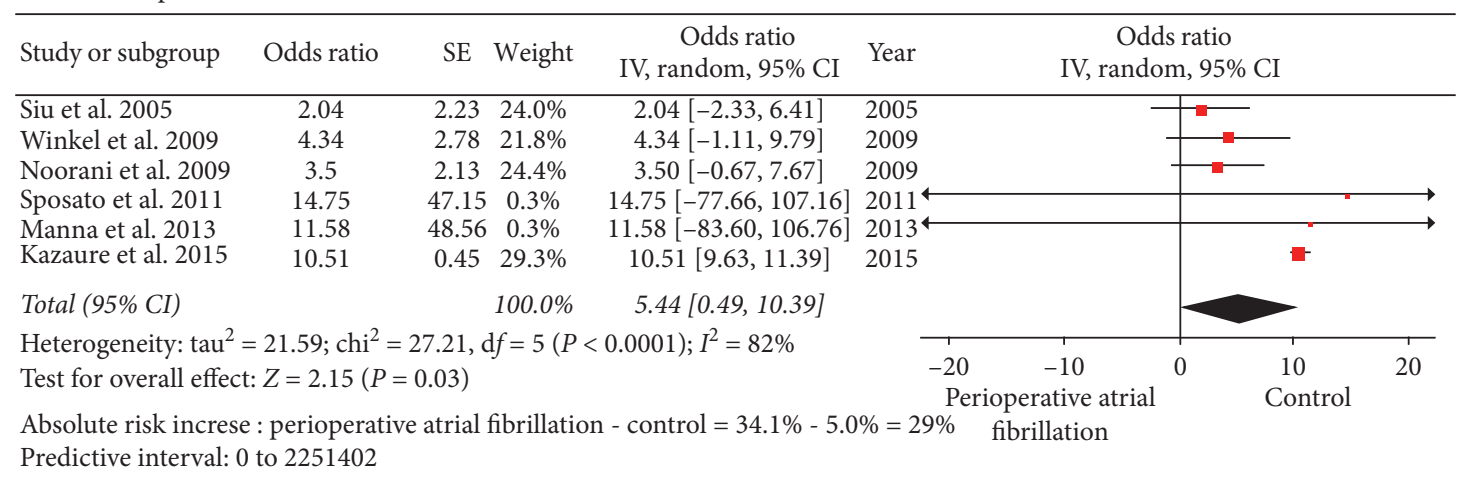

FIgURE 7: Forest plot comparing cardiac complications between atrial fibrillation group and control groups in patients undergoing noncardiothoracic surgery. The odds ratio of each included study is plotted. A pooled estimate of overall odds ratio (diamonds) and $95 \%$ confidence intervals (width of diamonds) summarizes the effect size using the random effects model. CI=confidence interval; $\mathrm{M}-\mathrm{H}=$ Mantel-Haenszel; OR = odds ratio; $I^{2}$ : heterogeneity; $P<0.05$ is significant.

\begin{tabular}{lccccccc} 
Mortality & & & \\
\hline Study or subgroup & Odds ratio & SE & Weight & $\begin{array}{c}\text { Odds ratio } \\
\text { IV, random, 95\% CI }\end{array}$ & Year & Odds ratio \\
IV, random, 95\% CI
\end{tabular}

Figure 8: Forest plot comparing mortality between atrial fibrillation group and control groups in patients undergoing noncardiothoracic surgery. The odds ratio of each included study is plotted. A pooled estimate of overall odds ratio (diamonds) and $95 \%$ confidence intervals (width of diamonds) summarizes the effect size using the random effects model. $\mathrm{CI}=$ confidence interval; $\mathrm{M}-\mathrm{H}=\mathrm{Mantel}-\mathrm{Haenszel}$; $\mathrm{OR}=$ odds ratio; $I^{2}$ : heterogeneity; $P<0.05$ is significant.

(good versus poor-moderate), whether or not outcomes were clearly defined (yes versus no), sample size >1000 (yes versus no), and surgery type (transplant versus nontransplant procedures) did not show any significant differences in the results (Table 1).

\section{Discussion}

There is a change in the old perception that postoperative arrhythmias like AF were a benign condition [31, 32]. Newly diagnosed AF is identified as a risk factor for stroke, prolonged hospital stay, and hospitalization costs [21]. This SRMA of the risk factors and outcomes of perioperative AF associated with noncardiothoracic surgery identified advanced age, male gender, preexisting cardiac comorbidities, hypertension, and diabetes mellitus as the risk factors associated with perioperative AF. The AF group had increased odds for perioperative cardiac complications, stroke, and mortality compared to the non-AF group.
Evidence on the incidence of postoperative arrhythmias shows that $16 \%$ to $46 \%$ of patients after cardiac surgery, $3 \%$ to $30 \%$ of patients after thoracic surgery, and up to $8 \%$ of noncardiothoracic surgical patients developed new-onset atrial arrhythmias [33]. Evidence on the incidence of AF after noncardiothoracic surgery is largely variable. From the studies included in our analysis, we calculated an incidence of $2.49 \%$. Sohn et al. [27] reported that $0.39 \%$ of patients experienced postoperative atrial fibrillation (POAF) after noncardiothoracic surgery, similar to the $0.37 \%$ found by Christians et al. [34], abdominal surgery is associated with a higher incidence of perioperative AF versus other noncardiothoracic surgical procedures [35]. Kazaure et al. [21] found that 1 in 8 patients over 65 years, and 1 in 4 patients over 85 years, had AF after abdominal surgery. This is also confirmed by our analysis which showed that $90.87 \%$ of the patients in the arrhythmia group had abdominal or general surgery. A literature review and analysis [36] showed that the majority of perioperative arrhythmias are supraventricular in origin and AF was the single most common arrhythmia. 
TABLe 1: Study quality assessment: meta-regression and sensitivity analysis of various subgroups (as categorical variable).

\begin{tabular}{|c|c|c|c|c|c|c|}
\hline $\begin{array}{l}\text { Risk factor or outcome } \\
\text { Age }\end{array}$ & $\begin{array}{l}\text { Study characteristics (number of studies) } \\
\text { Coefficient (SE) }\end{array}$ & $\begin{array}{l}\text { Summary estimate } \\
P \text { value }\end{array}$ & $95 \% \mathrm{CI}$ & $I^{2}$ & Meta-regression & ression \\
\hline Study type & $\begin{array}{l}\text { Retrospective (9) }[19-23,26-29] \\
\text { Prospective }(2)[24,25]\end{array}$ & $\begin{array}{l}3.75 \\
5.03\end{array}$ & $\begin{array}{l}0.75-6.76 \\
2.97-7.09\end{array}$ & $\begin{array}{c}90 \\
0\end{array}$ & $\begin{array}{c}0.6155 \\
(3.6220)\end{array}$ & 0.8651 \\
\hline Quality of study & $\begin{array}{l}\text { Poor-moderate (1) [20] } \\
\text { Good }(10)[19,20-29]\end{array}$ & $\begin{array}{c}14.34 \\
3.97\end{array}$ & $\begin{array}{c}-11.37-40.05 \\
1.57-6.38\end{array}$ & $\overline{89}$ & $\begin{array}{l}-0.3148 \\
(4.8794)\end{array}$ & 0.9486 \\
\hline Outcome defined & $\begin{array}{c}\text { Yes }(7)[19,21,22,24,25,27,28] \\
\text { No }(4)[20,23,26,29]\end{array}$ & $\begin{array}{l}4.58 \\
3.12\end{array}$ & $\begin{array}{c}2.08-7.08 \\
-4.31-10.55\end{array}$ & $\begin{array}{l}88 \\
83\end{array}$ & $\begin{array}{c}0.3634 \\
(3.8607)\end{array}$ & 0.9250 \\
\hline Sample size $>1000$ & $\begin{array}{l}\text { Yes (4) }[21,25-27] \\
\quad \text { No }(7)[19,20,22-24,28,29]\end{array}$ & $\begin{array}{l}3.11 \\
4.93\end{array}$ & $\begin{array}{c}-0.41-6.62 \\
1.51-8.34\end{array}$ & $\begin{array}{l}94 \\
67\end{array}$ & $\begin{array}{c}1.9924 \\
(2.7880)\end{array}$ & 0.4748 \\
\hline Surgery type & $\begin{array}{c}\text { Transplant }(3)[25,26,29] \\
\text { Nontransplant }(8)[19-24,27,28]\end{array}$ & $\begin{array}{l}3.04 \\
4.42 \\
\end{array}$ & $\begin{array}{c}-4.03-10.11 \\
1.68-7.17 \\
\end{array}$ & $\begin{array}{l}90 \\
86\end{array}$ & $\begin{array}{l}-1.6709 \\
(3.9716)\end{array}$ & 0.6740 \\
\hline Gender & & & & & & \\
\hline Study type & $\begin{array}{l}\text { Retrospective (9) }[19-23,26-29] \\
\text { Prospective }(2)[24,25]\end{array}$ & $\begin{array}{l}1.07 \\
1.15\end{array}$ & $\begin{array}{l}0.42-1.72 \\
0.66-1.64\end{array}$ & $\begin{array}{c}87 \\
0\end{array}$ & $\begin{array}{l}-0.1621 \\
(0.7248)\end{array}$ & 0.8230 \\
\hline Quality of study & $\begin{array}{l}\text { Poor-moderate (1) [20] } \\
\text { Good (10) }[19,21-29]\end{array}$ & $\begin{array}{l}0.68 \\
1.14\end{array}$ & $\begin{array}{c}-0.26-1.62 \\
0.55-1.72\end{array}$ & $\overline{86}$ & $\begin{array}{l}-0.5386 \\
(0.9223)\end{array}$ & 0.5592 \\
\hline Outcome defined & $\begin{array}{c}\text { Yes (7) }[19,21,22,24,25,27,28] \\
\text { No }(4)[20,23,26,29]\end{array}$ & $\begin{array}{l}1.43 \\
0.56\end{array}$ & $\begin{array}{c}1.33-1.52 \\
-0.01-1.12\end{array}$ & $\begin{array}{c}0 \\
34\end{array}$ & $\begin{array}{c}0.4614 \\
(0.7465)\end{array}$ & 0.5366 \\
\hline Sample size $>1000$ & $\begin{array}{c}\text { Yes (4) }[21,25-27] \\
\text { No (7) }[19,20,22-24,28,29]\end{array}$ & $\begin{array}{l}1.07 \\
1.02\end{array}$ & $\begin{array}{l}0.29-1.86 \\
0.46-1.57\end{array}$ & $\begin{array}{c}95 \\
0\end{array}$ & $\begin{array}{l}-0.3247 \\
(0.4793)\end{array}$ & 0.4981 \\
\hline Surgery type & $\begin{array}{c}\text { Transplant (3) }[25,26,29] \\
\text { Nontransplant }(8)[19-24,27,28] \\
\end{array}$ & $\begin{array}{l}0.80 \\
1.43 \\
\end{array}$ & $\begin{array}{c}-0.04-1.63 \\
1.33-1.53 \\
\end{array}$ & $\begin{array}{c}83 \\
0 \\
\end{array}$ & $\begin{array}{l}-0.3795 \\
(0.7126)\end{array}$ & 0.5944 \\
\hline Hypertension & & & & & & \\
\hline Study type & $\begin{array}{c}\text { Retrospective }(8)[19,21-23,26-29] \\
\text { Prospective }(2)[24,25]\end{array}$ & $\begin{array}{l}1.15 \\
1.24\end{array}$ & $\begin{array}{l}1.07-1.22 \\
0.75-1.74\end{array}$ & $\begin{array}{l}0 \\
0\end{array}$ & $\begin{array}{l}-0.1036 \\
(0.5441)\end{array}$ & 0.8490 \\
\hline Quality of study & $\begin{array}{l}\text { Poor-moderate (0) } \\
\text { Good (10) }[19,21-29]\end{array}$ & - & $\begin{array}{c}- \\
1.08-1.23\end{array}$ & $\overline{0}$ & - & - \\
\hline Outcome defined & $\begin{array}{c}\text { Yes }(7)[19,21,22,24,25,27,28] \\
\text { No }(3)[23,26,29]\end{array}$ & $\begin{array}{l}1.15 \\
2.81\end{array}$ & $\begin{array}{c}1.08-1.23 \\
-0.77-6.39\end{array}$ & $\begin{array}{l}0 \\
0\end{array}$ & $\begin{array}{l}-0.8519 \\
(0.6469)\end{array}$ & 0.1879 \\
\hline Sample size $>1000$ & $\begin{array}{c}\text { Yes (4) }[21,25-27] \\
\text { No }(6)[19,22-24,28,29]\end{array}$ & $\begin{array}{l}1.15 \\
1.32\end{array}$ & $\begin{array}{l}1.08-1.23 \\
0.50-2.13\end{array}$ & $\begin{array}{l}0 \\
0\end{array}$ & $\begin{array}{l}-0.2608 \\
(0.2933)\end{array}$ & 0.3738 \\
\hline Surgery type & $\begin{array}{c}\text { Transplant (3) }[25,26,29] \\
\text { Nontransplant }(7)[19,21-24,27,28]\end{array}$ & $\begin{array}{l}1.24 \\
1.15 \\
\end{array}$ & $\begin{array}{l}0.74-1.75 \\
1.07-1.23 \\
\end{array}$ & $\begin{array}{l}0 \\
0\end{array}$ & $\begin{array}{l}-0.0418 \\
(0.5639)\end{array}$ & 0.9409 \\
\hline Cardiac disease & & & & & & \\
\hline Study type & $\begin{array}{c}\text { Retrospective (7) }[19,21-23,26,28,29] \\
\text { Prospective (2) }[24,25]\end{array}$ & $\begin{array}{l}2.79 \\
1.32\end{array}$ & $\begin{array}{l}0.17-5.41 \\
0.16-2.49\end{array}$ & $\begin{array}{l}92 \\
55\end{array}$ & $\begin{array}{c}1.3910 \\
(0.7236)\end{array}$ & 0.0545 \\
\hline Quality of study & $\begin{array}{c}\text { Poor-moderate }(0) \\
\text { Good (9) }[19,21-26,28,29]\end{array}$ & - & $0.28-4.31$ & $\overline{93}$ & - & - \\
\hline Outcome defined & $\begin{array}{c}\text { Yes (6) }[19,21,22,24,25,28] \\
\text { No }(3)[23,26,29]\end{array}$ & $\begin{array}{l}2.15 \\
3.28\end{array}$ & $\begin{array}{l}-0.16-4.46 \\
-1.90-8.46\end{array}$ & $\begin{array}{l}95 \\
27\end{array}$ & $\begin{array}{c}0.0043 \\
(0.7790)\end{array}$ & 0.9956 \\
\hline Sample size $>1000$ & $\begin{array}{c}\text { Yes (3) }[21,25,26] \\
\text { No (6) }[19,22-24,28,29]\end{array}$ & $\begin{array}{l}3.86 \\
0.94\end{array}$ & $\begin{array}{l}0.90-6.82 \\
0.29-1.58\end{array}$ & $\begin{array}{c}92 \\
0\end{array}$ & $\begin{array}{c}0.7579 \\
(0.5663)\end{array}$ & 0.1808 \\
\hline Surgery type & $\begin{array}{c}\text { Transplant (3) }[25,26,29] \\
\text { Nontransplant }(6)[19,21-24,28]\end{array}$ & $\begin{array}{l}2.94 \\
2.01\end{array}$ & $\begin{array}{l}-0.63-6.52 \\
-0.42-4.44\end{array}$ & $\begin{array}{l}13 \\
96\end{array}$ & $\begin{array}{c}0.9274 \\
(0.7732)\end{array}$ & 0.2304 \\
\hline Diab & & & & & & \\
\hline Study type & $\begin{array}{c}\text { Retrospective (8) }[19,21-23,26-29] \\
\text { Prospective (1) [24] }\end{array}$ & $\begin{array}{l}0.97 \\
0.61\end{array}$ & $\begin{array}{c}0.89-1.05 \\
-0.70-1.92\end{array}$ & $\begin{array}{l}0 \\
-\end{array}$ & $\begin{array}{c}0.7277 \\
(0.8681)\end{array}$ & 0.4019 \\
\hline Quality of study & $\begin{array}{c}\text { Poor-moderate (0) } \\
\text { Good (9) }[19,21-24,26-29]\end{array}$ & - & $\begin{array}{c}- \\
0.89-1.05\end{array}$ & $\overline{0}$ & - & - \\
\hline Outcome defined & $\begin{array}{c}\text { Yes }(6)[19,21,22,24,27,28] \\
\text { No }(3)[23,26,29]\end{array}$ & $\begin{array}{l}0.97 \\
1.51\end{array}$ & $\begin{array}{l}0.89-1.05 \\
0.14-2.88\end{array}$ & $\begin{array}{l}0 \\
0\end{array}$ & $\begin{array}{l}-0.2032 \\
(0.6595)\end{array}$ & 0.7579 \\
\hline Sample size $>1000$ & $\begin{array}{c}\text { Yes }(3)[21,26,27] \\
\text { No }(6)[19,22-24,28,29]\end{array}$ & $\begin{array}{l}0.97 \\
0.94\end{array}$ & $\begin{array}{l}0.89-1.05 \\
0.17-1.71\end{array}$ & $\begin{array}{l}0 \\
0\end{array}$ & $\begin{array}{l}-0.2644 \\
(0.3968)\end{array}$ & 0.5052 \\
\hline Surgery type & $\begin{array}{c}\text { Transplant }(2)[26,29] \\
\text { Nontransplant }(7)[19,21-24,27,28]\end{array}$ & $\begin{array}{l}1.48 \\
0.97\end{array}$ & $\begin{array}{c}-0.51-3.48 \\
0.89-1.05\end{array}$ & $\begin{array}{l}0 \\
0\end{array}$ & $\begin{array}{c}0.3992 \\
(0.7410)\end{array}$ & 0.5901 \\
\hline
\end{tabular}


TABLE 1: Continued.

\begin{tabular}{|c|c|c|c|c|c|c|}
\hline $\begin{array}{l}\text { Risk factor or outcome } \\
\text { Age }\end{array}$ & $\begin{array}{l}\text { Study characteristics (number of studies) } \\
\text { Coefficient (SE) }\end{array}$ & $\begin{array}{l}\text { Summary estimate } \\
P \text { value }\end{array}$ & $95 \% \mathrm{CI}$ & $I^{2}$ & Meta-regression & ession \\
\hline \multicolumn{7}{|l|}{ Cardiac complications } \\
\hline \multirow{2}{*}{ Study type } & Retrospective (5) $[19,21,22,28,29]$ & 5.71 & $-0.18-11.61$ & 83 & 0.3609 & \multirow{2}{*}{0.6949} \\
\hline & Prospective (1) [24] & 4.34 & $-1.11-9.79$ & - & $(0.9292)$ & \\
\hline Quality of study & $\begin{array}{l}\text { Poor-moderate }(0) \\
\end{array}$ & - & - & $\overline{82}$ & \multicolumn{2}{|r|}{-} \\
\hline \multirow{2}{*}{ Outcome defined } & Yes $(5)[19,21,22,24,28]$ & 5.41 & $0.36-10.46$ & 85 & -0.7377 & \multirow{2}{*}{0.6474} \\
\hline & No (1) [29] & 11.58 & $-83.6-106.76$ & 0 & $(1.6127)$ & \\
\hline \multirow{2}{*}{ Sample size $>1000$} & Yes (1) [21] & 10.51 & $9.63-11.39$ & - & 0.9718 & \multirow{2}{*}{0.0023} \\
\hline & No (5) $[19,22,24,28,29]$ & 3.18 & $0.54-5.82$ & 0 & $(0.3193)$ & \\
\hline \multirow{2}{*}{ Surgery type } & Transplant (1) [29] & 11.58 & $-83.60-106.76$ & - & 0.7377 & \multirow{2}{*}{0.6474} \\
\hline & Nontransplant (5) $[19,21,22,24,28]$ & 5.41 & $0.36-10.46$ & 85 & $(1.6127)$ & \\
\hline \multicolumn{7}{|l|}{ Mortality } \\
\hline \multirow{2}{*}{ Study type } & Retrospective (6) $[19,20,22,26-28]$ & 3.58 & $0.14-7.02$ & 0 & & \multirow{2}{*}{-} \\
\hline & Prospective $(0)$ & - & - & - & & \\
\hline \multirow{2}{*}{ Quality of study } & Poor-moderate (1) [20] & 2.47 & $-22.62-27.56$ & - & -0.7977 & \multirow{2}{*}{0.6530} \\
\hline & Good (5) $[19,22,26-28]$ & 3.60 & $0.13-7.08$ & 0 & $(1.7743)$ & \\
\hline \multirow{2}{*}{ Outcome defined } & Yes $(4)[19,22,27,28]$ & 3.20 & $-1.16-7.57$ & 0 & 0.4607 & \multirow{2}{*}{0.6670} \\
\hline & No $(2)[20,26]$ & 4.21 & $-1.39-9.81$ & 0 & $(1.0705)$ & \\
\hline \multirow{2}{*}{ Sample size $>1000$} & Yes (2) $[26,27]$ & 6.51 & $-3.79-16.81$ & 22 & 1.2296 & \multirow{2}{*}{0.0934} \\
\hline & No $(4)[19,20,22,28]$ & 2.69 & $-1.67-7.06$ & 0 & $(0.7329)$ & \\
\hline \multirow{2}{*}{ Surgery type } & Transplant (1) [26] & 4.30 & $-1.44-10.04$ & - & -0.2072 & \multirow{2}{*}{0.8651} \\
\hline & Nontransplant (5) $[19,20,22,27,28]$ & 3.18 & $-1.12-7.48$ & 0 & $(1.2196)$ & \\
\hline
\end{tabular}

Study quality scores were obtained from the Ottawa-Newcastle quality assessment [16]. Study was considered good when assigned score was equal 9. For respiratory complications and Stroke, meta-regression analysis not conducted due to inadequate number of studies.

Recognizing the risk factors of perioperative AF helps to individualize patient care, as well as to guide future studies of interventions to lower the incidence of perioperative $\mathrm{AF}$ and the associated complications. Age is an important predictor of perioperative AF. Our study found that the perioperative AF group patients were older compared to the control group. This is consistent with the findings from other studies $[20,24,27]$. Three studies have identified age as an independent predictor for perioperative $\mathrm{AF}$ in a multivariate analysis $[25,27,29]$. A prospective observational study of noncardiothoracic surgical patients [37] found that the average age of patients with new onset of atrial arrhythmias was around 67 years. But this study reported on atrial flutter, paroxysmal supraventricular tachycardia, and multifocal atrial tachycardia, in addition to AF. Likewise, Manna et al. [29] identified an age cut-off value of 53 years for the incidence of POAF after renal transplant surgery, but the authors agree that their study was inadequately powered to identify a real cut-off threshold of AF in this patient population. A study found that female sex was associated with a lower-risk of postoperative AF [21], which is in agreement with the findings of this meta-analysis.

We identified hypertension and diabetes as predictors of perioperative arrhythmias. Hypertension is well established to be a risk factor for perioperative $\mathrm{AF}$ in both experimental animal and human studies $[38,39]$. The probable hemodynamic mechanisms include the increase in left ventricular wall thickness, stiffness, that may lead to a rise in left atrial stretch and pressure, and subsequent remodeling, ultimately predisposing to AF [40]. Studies have indicated that inflammation associated with diabetes might play a role in the pathophysiology of AF and a multivariate analysis from a community study showed that DM is independently associated with AF (OR: 1.46) [41].

In our review, increased BMI was not identified as a risk factor for perioperative AF. However, BMI was identified as an important risk factor of new-onset atrial fibrillation (NOAF) after cardiac surgery [42]. Interestingly, Sohn et al.'s study [27] of noncardiothoracic surgery patients found the opposite result, as the patients with AF had a significantly lower BMI versus patients without AF. Although additional studies are required, the authors have attributed this to the obesity paradox, which holds that obesity may in fact be protective and associated with greater survival in certain groups, like the elderly [43].

In our analysis, preexisting cardiac disease increases the odds of perioperative AF. In a study by Christians et al. [34], of POAF in noncardiothoracic surgical patients, at least one cardiac risk factor was found in $67 \%$ percent of the patients. This study did not include a control group and hence was not included in our analysis.

Fulminant hepatic failure and a higher MELD score were identified as independent predictors of intraoperative $\mathrm{AF}$ $[25,26]$. In our study, the MELD score was not a significant predictor of perioperative AF in liver transplant patients. The sympathetic hyperfunction and autonomic imbalance is attributable to the heart rate variability changes in patients with liver failure [44].

Perioperative AF after noncardiothoracic surgery has been associated with poor postoperative cardiovascular outcomes. Our meta-analysis found that perioperative AF was associated with increased odds of postoperative cardiac 
complications, like myocardial infarction (MI) and congestive cardiac failure. Four studies have identified perioperative $\mathrm{AF}$ as an independent predictor for postoperative cardiac complications in a multivariate analysis $[19,21,24,29]$. NOAF was found to be associated with MI and stroke after carotid endarterectomy [22]. A retrospective study on patients undergoing aortic repair by Noorani et al. [19] found that NOAF was associated with a greater risk of MI, which should be seriously considered in case of a NOAF after surgery involving the aorta. Our study also found that cardiac failure was independently associated with AF. In another study by Winkel et al. [24], a strong association between AF and myocardial ischemia was seen, as evidenced by an increased release of troponin T. However, the temporal relationship between myocardial ischemia and $\mathrm{AF}$ could not be proved as troponin $\mathrm{T}$ was only measured at intervals. Furthermore, myocardial ischemia preceded the onset of NOAF in about half of the cases.

Our study found increased odds of mortality in the AF group versus the control group. Several other studies $[33,45]$, examining AF following noncardiothoracic surgery reported a mortality increase. Two studies have identified perioperative $\mathrm{AF}$ as an independent predictor for postoperative mortality in a multivariate analysis [21, 26]. Our finding is also consistent with the findings of Leibowitz et al. [23] who reported a significant increase in one-year mortality in patients with $\mathrm{AF}$ versus those without $\mathrm{AF}$ after hip fracture surgery $(60 \%$ versus $19.5 \% ; P=0.001)$ that is not attenuated by antiarrhythmic therapy to treat AF. There are several reasons attributed to this increased mortality in AF patients after hip fracture surgery. The loss of effective atrial contraction secondary to AF is associated with hemodynamic decompensation and thromboembolic events $[46,47]$. Elderly patients are particularly dependent on atrial contraction for ventricular filling as they commonly suffer from noncompliant left ventricles and are more vulnerable to this complication of AF [48, 49]. Similarly, another study reported a significantly higher one-year mortality in elderly adults with atrial arrhythmias after surgery for hip fracture, but this study included patients with preoperative AF [50]. Christians et al. [34] reported a one-month mortality of $12 \%$ in AF patients after noncardiothoracic surgery. In another study of oncological surgical procedures, the in-hospital mortality and long-term mortality were $14 \%$ and $41 \%$, respectively [51]. But it is noteworthy that no control population was included in both the above studies. Intraoperative $\mathrm{AF}$ was found to be an independent predictor of postoperative mortality with a 4.5 times higher risk of mortality after liver transplantation, despite its low incidence (1.2\%) and short duration (1 hour) [26]. This is attributed to the increased stress on the cardiovascular system, with large perioperative fluid shifts, hemodynamic changes, and also because of the aggressive treatment of intraoperative hemorrhage with aggressive vasopressor and fluid therapy [52]. A subgroup analysis also allowed us to shed light on the group of transplant surgical patients: it showed an increased mortality rate and postoperative cardiac complications in the arrhythmia group, regardless of the presence of other risk factors such as advanced age, history of cardiac disease, and hypertension which were not significant in this population.

4.1. Limitations. The lack of consistent definition, precision in identifying $\mathrm{AF}$, and consistent monitoring protocols are major risks for bias in many of the included studies. The application of cardiac monitoring intraoperatively was reported in only 2 studies [22,26], although it may be assumed that all patients are likely to have continuous monitoring in the intraoperative period. Three studies $[19,22,24]$ applied continuous cardiac monitoring for at least 72 hours, and four studies $[23,25,27,28]$ reported conducting "regular" ECGs in the postoperative setting. The second limitation is that although studies included in our SRMA did not include patients with preoperative AF, not every study would have screened the patients for preoperative AF. Third, studies included in this SRMA were observational studies with a higher likelihood of intrinsic bias and may have contributed to a high degree of heterogeneity in our results. Fourth, the confounding effect on the risk factors is another limitation. Although the majority of the included studies performed multivariate regression analysis to correct for confounding variables, we were unable to pool the adjusted risk estimates and outcomes as they were sparsely reported for all the prognostic factors and the studies greatly differed in the number and the type of prognostic factors that were adjusted in the regression analyses. Furthermore, the causality relationship between perioperative $\mathrm{AF}$ and postoperative complications may not be conclusive owing to the retrospective nature of majority of the included studies. However, our meta-regression analysis would help in overcoming these biases to some extent. Lastly, even though publication bias was ruled out by multiple tests (Egger's regression test, Begg's rank test, and fail-safe $N$ test), complete absence of publication bias cannot be ruled out. Hence, a well-designed prospective study with uniform definition, monitoring and follow-up for AF would help to perform risk stratification and to identify the outcomes and prognosis of the patients with perioperative AF.

\section{Conclusion}

This SRMA identified advanced age, male gender, preexisting hypertension, diabetes mellitus, and cardiac disease as important risk factors associated with perioperative AF. We also found that the AF group had increased odds for postoperative cardiac complications, stroke, and higher mortality compared to the control group, emphasizing the need for risk stratification and close monitoring of this surgical population.

\section{Abbreviations}

AF: $\quad$ Atrial Fibrillation

BMI: $\quad$ Body mass index

CI: $\quad$ Confidence Interval

CMA: Comprehensive Meta-Analysis

ECG: Electrocardiogram

MD: $\quad$ Mean Difference 
MELD: Model for End-stage Liver Disease

NOAF: New-Onset Atrial Fibrillation

OR: $\quad$ Odds Ratios

PRISMA: Preferred Items for Systematic Reviews and Meta-Analyses

QUIPS: Quality in Prognostic Studies

SRMA: Systematic Review and Meta-analysis

\section{Data Availability}

The data are available upon request to the corresponding author.

\section{Disclosure}

Yamini Subramani and Omar El Tohamy share the first authorship.

\section{Conflicts of Interest}

The authors declare no conflicts of interest.

\section{Authors' Contributions}

All authors have read and approved the manuscript. YS designed the study, reviewed the literature, performed data collection and analysis, and prepared the manuscript. OT helped in reviewing the literature, data collection, and analysis. DJ helped in reviewing the literature, data collection, and analysis. MN helped with statistical analysis and preparing and editing the manuscript. HY helped with analysis and preparing and editing the manuscript. $\mathrm{AF}$ helped in designing the study, data collection, analysis, preparing, and editing the manuscript.

\section{Acknowledgments}

The authors thank Rachel Sandieson, Librarian, and Brie McConnell MLIS (Media and Information Manager, London Health Science Centre, Western University) for their assistance with the literature search.

\section{Supplementary Materials}

S1: predesigned study protocol. S2: study search strategy. S3: definitions of outcome atrial fibrillation. S4: table on systematic review. S5: Newcastle-Ottawa scale scoring system (quantitative study assessment). S6: bias assessment results of each study with the quality in prognostic studies (QUIPS) tool. S7: distribution of the type of surgical procedures for the atrial fibrillation group and control groups. (Supplementary Materials)

\section{References}

[1] R. P. Villareal, R. Hariharan, B. C. Liu et al., "Postoperative atrial fibrillation and mortality after coronary artery bypass surgery," Journal of the American College of Cardiology, vol. 43, no. 5, pp. 742-748, 2004.
[2] G. H. Almassi, T. Schowalter, A. C. Nicolosi et al., "Atrial fibrillation after cardiac surgery," Annals of Surgery, vol. 226, no. 4, pp. 501-513, 1997.

[3] S.-H. Lee, D. R. Kang, J.-S. Uhm et al., "New-onset atrial fibrillation predicts long-term newly developed atrial fibrillation after coronary artery bypass graft," American Heart Journal, vol. 167, no. 4, pp. 593-600, 2014.

[4] J. P. Mathew, "Atrial fibrillation following coronary artery bypass graft surgery," JAMA, vol. 276, no. 4, pp. 300-306, 1996.

[5] P. D. Bhave, L. E. Goldman, E. Vittinghoff, J. Maselli, and A. Auerbach, "Incidence, predictors, and outcomes associated with postoperative atrial fibrillation after major noncardiac surgery," American Heart Journal, vol. 164, no. 6, pp. 918-924, 2012.

[6] F. D. Murgatroyd and A. J. Camm, "Current concepts in atrial fibrillation," British Journal of Hospital Medicine, vol. 49, pp. 546-549, 1993.

[7] M. K. Chung, D. O. Martin, D. Sprecher et al., "C-reactive protein elevation in patients with atrial arrhythmias," Circulation, vol. 104, no. 24, pp. 2886-2891, 2001.

[8] R. Udelsman, D. S. Goldstein, D. L. Loriaux, and G. P. Chrousos, "Catecholamine-glucocorticoid interactions during surgical stress," Journal of Surgical Research, vol. 43, no. 6, pp. 539-545, 1987.

[9] K. Furuya, R. Shimizu, Y. Hirabayashi, R. Ishii, and H. Fukuda, "Stress hormone responses to major intraabdominal surgery during and immediately after sevoflurane-nitrous oxide anaesthesia in elderly patients," Canadian Journal of Anaesthesia, vol. 40, no. 5, pp. 435439, 1993.

[10] K. A. Arsenault, A. M. Yusuf, E. Crystal et al., "Interventions for preventing post-operative atrial fibrillation in patients undergoing heart surgery," Cochrane Database of Systematic Reviews, vol. 2013, no. 1, Article ID CD003611, 2013.

[11] R. M. Melduni, H. V. Schaff, K. R. Bailey et al., "Implications of new-onset atrial fibrillation after cardiac surgery on longterm prognosis: a community-based study," American Heart Journal, vol. 170, no. 4, pp. 659-668, 2015.

[12] C. Martinez, A. Katholing, C. Wallenhorst, S. Granziera, A. T. Cohen, and S. B. Freedman, "Increasing incidence of non-valvular atrial fibrillation in the UK from 2001 to 2013," Heart, vol. 101, no. 21, pp. 1748-1754, 2015.

[13] K. Oakland, R. Nadler, L. Cresswell, D. Jackson, and P. Coughlin, "Systematic review and meta-analysis of the association between frailty and outcome in surgical patients," The Annals of The Royal College of Surgeons of England, vol. 98, no. 2, pp. 80-85, 2016.

[14] A. F. M. Scholz, C. Oldroyd, K. McCarthy, T. J. Quinn, and J. Hewitt, "Systematic review and meta-analysis of risk factors for postoperative delirium among older patients undergoing gastrointestinal surgery," British Journal of Surgery, vol. 103, no. 2, pp. e21-e28, 2016.

[15] D. Moher, A. Liberati, J. Tetzlaff, D. G. Altman, and PRISMA Group, "Preferred reporting Items for systematic reviews and meta-analyses: the PRISMA statement," Annals of Internal Medicine, vol. 151, no. 4, p. 264, 2009.

[16] G. Wells, B. Shea, D. O'connell, J. Peterson, and V. L. Welch, The Newcastle-Ottawa Scale (NOS) for Assessing the Quality if Nonrandomized Studies in Meta-Analyses, http://www.ohri. ca/programs/clinical_epidemiology/oxford.asp, 2014.

[17] J. A. Hayden, P. Côté, and C. Bombardier, "Evaluation of the quality of prognosis studies in systematic reviews," Annals of Internal Medicine, vol. 144, no. 6, pp. 427-437, 2006. 
[18] J. P. T. Higgins, S. G. Thompson, J. J. Deeks, and D. G. Altman, "Measuring inconsistency in meta-analyses," BMJ, vol. 327, no. 7414, pp. 557-560, 2003.

[19] A. Noorani, S. R. Walsh, T. Y. Tang et al., "Atrial fibrillation following elective open abdominal aortic aneurysm repair," International Journal of Surgery, vol. 7, no. 1, pp. 24-27, 2009.

[20] I. C. Botwinick, R. J. Shonkwiler, J. Steele, G. Yu, and J. A. Chabot, "Atrial fibrillation and delayed gastric emptying," PLoS One, vol. 6, Article ID e25499, 2011.

[21] H. S. Kazaure, S. A. Roman, D. Tyler, and J. A. Sosa, "The significance of atrial fibrillation in patients aged $\geq 55$ years undergoing abdominal surgery," World Journal of Surgery, vol. 39, no. 1, pp. 113-120, 2015.

[22] L. A. Sposato, A. Suárez, A. Jáuregui et al., "Intraoperative hypotension, new onset atrial fibrillation, and adverse outcome after carotid endarterectomy," Journal of the Neurological Sciences, vol. 309, no. 1-2, pp. 5-8, 2011.

[23] D. Leibowitz, C. Abitbol, R. Alcalai, G. Rivkin, and L. Kandel, "Perioperative atrial fibrillation is associated with increased one-year mortality in elderly patients after repair of hip fracture," International Journal of Cardiology, vol. 227, pp. 58-60, 2017.

[24] T. A. Winkel, O. Schouten, S. E. Hoeks, H. J. M. Verhagen, J. J. Bax, and D. Poldermans, "Prognosis of transient newonset atrial fibrillation during vascular surgery," European Journal of Vascular and Endovascular Surgery, vol. 38, no. 6, pp. 683-688, 2009.

[25] V. W. Xia, A. Worapot, S. Huang et al., "Postoperative atrial fibrillation in liver transplantation," American Journal of Transplantation, vol. 15, no. 3, pp. 687-694, 2015.

[26] Y.-J. Moon, H.-M. Kwon, Y.-S. Park, S.-H. Kim, and G.-S. Hwang, "Brief episodes of newly developed intraoperative atrial fibrillation predicts worse outcomes in adult liver transplantation," Transplantation Proceedings, vol. 50, no. 4, pp. 1142-1146, 2018.

[27] G. H. Sohn, D.-H. Shin, K. M. Byun et al., "The incidence and predictors of postoperative atrial fibrillation after noncardiothoracic surgery," Korean Circulation Journal, vol. 39, no. 3, pp. 100-104, 2009.

[28] C. W. Siu, H. M. Tung, K. W. Chu, M. H. Jim, C. P. Lau, and H. F. Tse, "Prevalence and predictors of new-onset atrial fibrillation after elective surgery for colorectal cancer," PACE-Pacing Clin Electrophysiol, vol. 28, 2005.

[29] G. L. Manna, G. Boriani, I. Capelli et al., "Incidence and predictors of postoperative atrial fibrillation in kidney transplant recipients," Transplantation, vol. 96, pp. 981-986, 2013.

[30] R. Dawkins, The Selfish Gene, Oxford University Press, New York, NY, USA, 1976.

[31] T. S. M. Tsang and B. J. Gersh, "Atrial fibrillation: an old disease, a new epidemic," The American Journal of Medicine, vol. 113, no. 5, pp. 432-435, 2002.

[32] D. C. Burgess, M. J. Kilborn, and A. C. Keech, "Interventions for prevention of post-operative atrial fibrillation and its complications after cardiac surgery: a meta-analysis," European Heart Journal, vol. 27, no. 23, pp. 2846-2857, 2006.

[33] S. E. Mayson, A. J. Greenspon, S. Adams et al., "The changing face of postoperative atrial fibrillation prevention," Cardiology in Review, vol. 15, no. 5, pp. 231-241, 2007.

[34] K. K. Christians, B. Wu, E. J. Quebbeman, and K. J. Brasel, "Postoperative atrial fibrillation in noncardiothoracic surgical patients," The American Journal of Surgery, vol. 182, no. 6, pp. 713-715, 2001.
[35] C. A. Polanczyk, L. Goldman, E. R. Marcantonio, E. J. Orav, and T. H. Lee, "Supraventricular arrhythmia in patients having noncardiac surgery: clinical correlates and effect on length of stay," Annals of Internal Medicine, vol. 129, no. 4, pp. 279-285, 1998.

[36] S. R. Walsh, T. Tang, C. Wijewardena, S. I. Yarham, J. R. Boyle, and M. E. Gaunt, "Postoperative arrhythmias in general surgical patients," The Annals of the Royal College of Surgeons of England, vol. 89, no. 2, pp. 91-95, 2007.

[37] D. Brathwaite and C. Weissman, "The new onset of atrial arrhythmias following major noncardiothoracic surgery is associated with increased mortality," Chest, vol. 114, no. 2, pp. 462-468, 1998.

[38] A. Goette, J. M. Kalman, L. Aguinaga et al., "EHRA/HRS/ APHRS/SOLAECE expert consensus on atrial cardiomyopathies: definition, characterization, and clinical implication," Europace, vol. 18, no. 10, pp. 1455-1490, 2016.

[39] D. H. Lau, N. J. Shipp, D. J. Kelly et al., "Atrial arrhythmia in ageing spontaneously hypertensive rats: unraveling the substrate in hypertension and ageing," PLoS One, vol. 8, Article ID e72416, 2013.

[40] P. Verdecchia, F. Angeli, and G. Reboldi, "Hypertension and atrial fibrillation," Circulation Research, vol. 122, no. 2, pp. 352-368, 2018.

[41] Y. Iguchi, K. Kimura, J. Aoki et al., "Prevalence of atrial fibrillation in community-dwelling Japanese aged 40 Years or older in Japan," Circulation Journal, vol. 72, no. 6, pp. 909-913, 2008.

[42] A. Zacharias, T. A. Schwann, C. J. Riordan, S. J. Durham, A. S. Shah, and R. H. Habib, "Obesity and risk of new-onset atrial fibrillation after cardiac surgery," Circulation, vol. 112, no. 21, pp. 3247-3255, 2005.

[43] J. P. Curtis, J. G. Selter, Y. Wang et al., "The obesity paradox," Archives of Internal Medicine, vol. 165, no. 1, p. 55, 2005.

[44] M. Fioranelli, M. Piccoli, G. M. Mileto et al., "Analysis of heart rate variability five minutes before the onset of paroxysmal atrial fibrillation," Pacing and Clinical Electrophysiology, vol. 22, no. 5, pp. 743-749, 1999.

[45] G. Mariscalco and K. G. Engström, "Postoperative atrial fibrillation is associated with late mortality after coronary surgery, but not after valvular surgery," The Annals of Thoracic Surgery, vol. 88, no. 6, pp. 1871-1876, 2009.

[46] R. S. Passman, D. S. Gingold, D. Amar et al., "Prediction rule for atrial fibrillation after major noncardiac thoracic surgery," The Annals of Thoracic Surgery, vol. 79, no. 5, pp. 1698-1703, 2005.

[47] D. Amar, A. Goenka, H. Zhang, B. Park, and H. T. Thaler, "Leukocytosis and increased risk of atrial fibrillation after general thoracic surgery," The Annals of Thoracic Surgery, vol. 82, no. 3, pp. 1057-1061, 2006.

[48] D. Amar, H. Zhang, S. Miodownik, and A. H. Kadish, "Competing autonomic mechanisms precedethe onset of postoperative atrial fibrillation," Journal of the American College of Cardiology, vol. 42, no. 7, pp. 1262-1268, 2003.

[49] G. Mariscalco and K. G. Engström, "Atrial fibrillation after cardiac surgery: risk factors and their temporal relationship in prophylactic drug strategy decision," International Journal of Cardiology, vol. 129, no. 3, pp. 354-362, 2008.

[50] B. P. Gupta, R. C. Steckelberg, R. E. Gullerud et al., "Incidence and 1-year outcomes of perioperative atrial arrhythmia in elderly adults after hip fracture surgery," Journal of the American Geriatrics Society, vol. 63, no. 11, pp. 2269-2274, 2015. 
[51] H. R. Gibbs, J. Swafford, H. D. Nguyen, M. S. Ewer, and M. K. Ali, "Postoperative atrial fibrillation in cancer surgery: preoperative risks and clinical outcome," Journal of Surgical Oncology, vol. 50, no. 4, pp. 224-227, 1992.

[52] J. Bargehr, J. F. Trejo-Gutierrez, T. Patel et al., "Preexisting atrial fibrillation and cardiac complications after liver transplantation," Liver Transplantation, vol. 21, no. 3, pp. 314-320, 2015. 